\title{
Peripheral Primitive Neuroectodermal Tumor of the Kidney
}

National Cancer Institute

\section{Source}

National Cancer Institute. Peripheral Primitive Neuroectodermal T umor of the Kidney. NCI Thesaurus. Code C67214.

A small round cell tumor with neural differentiation arising from the kidney. 